\title{
ROMA ANTE EL CAMBIO DINÁSTICO EN LA MONARQUÍA ESPAÑOLA. LA CONSULTA DE CARLOS II A INOCENCIO XII SOBRE LA SUCESIÓN
}

\section{DAVID MARTín MARCOS}

Escuela Española de Historia y Arqueología en Roma-CSIC

RESUMEN: Los problemas derivados de la falta de descendencia de Carlos II afectaron a toda Europa de finales del XVII. En la península italiana esta crísis se vivió con particular intensidad ya que una importante parte de sus territorios estaban controlados por la Monarquíaespañola. En este artículo se estudia el posicionamiento de Roma, tanto como poder temporal y espiritual, en la consulta que en 1700 Carlos II bizo a Inocencio XII sobre la sucesión a la corona de España.

Palabras Clave: Siglo XVII. Carlos II. Santa Sede. Italia. Diplomacia.

ABSTRACT: The problems derivated from the lack of Charles II'descendants affected the whole Europe at the end of the seventeenth century. In Italy this crisis was lived with particular intensity because an important part of its territories were controlled by the Spanish Monarchy. This article studies the role of Rome, as temporal and spiritual power, in the query maded to Innocent XII by Charles II in 1700 about the Spanish sucession.

KEY WORDS: Seventeenth Century. Charles II. Holly See. Italy. Diplomacy.

\section{LAS EMBAJADAS IMPERIAL Y FRANCESA EN ROMA}

Durante los últimos años del siglo XVII imperiales y franceses libraron en Madrid una batalla diplomática para ganarse el favor del moribundo Carlos II - $\mathrm{y}$ con él, su pingüe herencia-. De forma paralela, en otra capital europea, Roma, tanto unos como otros se batieron con las armas de la persuasión por ese mismo fin. Se pretendía que el pontífice, Inocencio XII (Antonio Pignatelli, 
1691-1700), de familia napolitana, y que consecuentemente había sido súbdito del monarca español, se pronunciase a favor de una u otra de las partes aspirantes a la sucesión. Los españoles, en cambio, hubieron de mantenerse a la expectativa en este escenario ya fuese por la larga vacancia efectiva del cargo de embajador tras la muerte del conde de Altamira, más de dos años, o por las timoratas instrucciones que se habían dado a su sucesor, el duque de Uceda ${ }^{1}$, para que mantuviese la tranquilidad en Italia y la aparente armonía con el pontífice 2 .

Atendiendo a este planteamiento, los protagonistas deberían ser, por parte del Imperio, el conde Georg Adam Martinitz, embajador en Roma desde enero de 1696 a octubre de 1699, cuando es sustituido por el conde Leopold Joseph de Lamberg, y, por parte de Francia, de Bouillon, vicedecano del Sacro Colegio de cardenales, y Luigi Grimaldi, el príncipe de Monaco. Si bien, fue más la sola actitud del primero la que, en parte, determinaría el parecer del Pontífice a la vigilia de la muerte de Carlos II.

La embajada de Martinitz ante Inocencio XII no era una tarea fácil; jugaba en su contra la inexistencia de una representación oficial imperial permanente en la ciudad desde la época de Fernando III con la misión del príncipe de Eggenberg, la falta de un cardenal de la nación alemana residente en Roma que no debiese ser compartido con los españoles y los problemas de su antecesor Anton Florian Liechtenstein ${ }^{3}$. Martinitz era además un hombre de temperamento pasional con gran devoción a la causa del emperador Leopoldo I y a las ideas absolutistas de la época. Lo demostró, según refiere Pastor ${ }^{4}$, poco tiempo después de su llegada a Roma, cuando, por pretender ocupar una posición de precedencia ante el Gobernador de Roma en la procesión del Corpus Domini y que los caballeros de su séquito ocupasen puestos de honor reservados a los cardenales, hizo retrasar «per lungo tempo» la ceremonia, haciendo esperar a la intemperie al pontífice. El incidente causó gran impresión entre la Curia e Inocencio XII pidió a sus cardenales que no participasen en la procesión nacional alemana de la iglesia de Santa Maria dell'Anima. Cuando la noticia llegó a Viena, Leopoldo I, pese a desaprobar la prepotencia de su embajador — que inclu-

1 En agosto de 1699 Carlos II nombró a su nuevo embajador, quien, extraviado su equipaje en un penoso viaje, no dio cuenta de su primera entrevista con Inocencio XII hasta el 21 de febrero de 1700. Cfr. OCHOA BRUn, M. A.: Embajadas rivales: La presencia diplomática de España en Italia durante la Guerra de Sucesión española, Madrid, 2002, p. 16

2 «Le sue Istruzioni si riducono a procurare la più perfetta armonia colle sodisfazioni di Sua Santità e della Sede Apostolica, e precisamente la quiete d'Italia. Mi persuado, che il Duca così farà essendo l'interesse comune», refiere el nuncio monseñor Archinto desde Madrid al cardenal Spada. ASV, Segr. Stato, Spagna, 180, ff. 327-328.

3 Cfr. GaRmS-CORNIDES, E.: Scene e attori della rappresentazione imperiale a Roma nell'ultimo Seicento, en Signorotto, G. y Visceglia, Mª. A.: La Corte di Roma tra Cinque e Seicento. "Teatro» della politica europea, Roma, 1998, pp. 509-535.

4 Cfr. Pastor, L.: Storia dei Papi, XIV, 2, Roma, 1962, pp. 491-494. 
so había difundido un manifiesto en Roma defendiendo su conducta 5 , manifestó que la abstención de los purpurados equivalía a un desprecio «della sua persona, e di tutta la nazione tedesca». El conflicto se radicalizó cuando al año siguiente, en 1697, el Papa rechazó de nuevo toda participación de los cardenales en la procesión y dispuso que para la fiesta del Corpus Domini se aboliesen los particulares acompañamientos de que disfrutaban cardenales y embajadores. Martinitz — continúa Pastor- llegó incluso a faltar al respeto al Papa Pignatelli y cuando en la Navidad de 1698 solicitó una audiencia para entrevistarse con él, no recibió ninguna respuesta.

El embajador era mantenido lejos de los círculos más influyentes de la Corte y sus posteriores tentativos por lograr una entrevista con el pontífice parecían inútiles. El Papa había puesto dos condiciones que, a los ojos de Martinitz, eran inaceptables: que la embajada imperial entregase a las autoridades pontificias a un hombre que retenía ilegalmente acusado de envenenamiento y que la audiencia de concederse fuese simplemente para despedirse de la corte. Las quejas de Martinitz a este respecto, recogidas en su correspondencia con el barón de Harrack ${ }^{6}$, están cargadas de indignación. En la petición de entrega del delincuente el embajador veía una violación de los derechos jurisdiccionales de su familia; en su muy probable licenciamiento una ofensa contra la autoridad del emperador ante la que había que mantenerse firme (y reforzar así su política de mano de hierro).

La importancia de los detalles protocolarios en la Corte de Roma a finales del XVII es un hecho indiscutible. Sin embargo, para comprender la negativa del pontífice a recibir a Martinitz en este episodio, junto a estos problemas de representación ha de valorarse otro aspecto. El 9 de junio de 1697 el embajador cesáreo hizo público un edicto en Roma en el que se recogían los supuestos derechos del Emperador sobre los feudos italianos. La respuesta de la Curia no tardó en llegar y el 17 de junio el cardenal Altieri, por orden del pontífice, publicaba un documento en el que se declaraban nulas las reivindicaciones de Leopoldo I y se prohibía a los supuestos feudatarios del Estado de la Iglesia cumplir con las órdenes imperiales, bajo pena de confiscación de propiedades. Aunque la polémica se disolvió poco tiempo después y «Cesare desistesse per allora dal mosso impegno e facesse delle rispettose scuse al sommo pontefice» ${ }^{7}$, esta novedad produjo en Roma cierto escepticismo sobre las verdaderas intenciones de Leopoldo I en relación al liderazgo de la península italiana ante la más que previsible extinción de la rama española de los Austrias, y no hizo sino

5 Cfr. Lettera in forma di manifesto del Conte di Martinitz, Ambasciatore Cesareo in giustificazione della sua condotta nel consaputo impegno per la processione del Corpus Domini l'anno 1696, Roma, 4 de julio de 1696. ASV, Fondo Bolognetti, 32, ff. 181-192.

6 Cfr. BrunetTi, M.: Il dissidio diplomatico cesareo-papale alla vigilia della successione di Spagna, «Nuova Rivista Storica», 22, 1938, pp. 200-223.

Muratori, L. A.: Annali d'Italia, LII, Venecia, 1834, p. 187. 
enredar aún más una situación que el propio Martinitz involuntariamente complicaba con sus escasas dotes de diplomático.

En los tres años que duró su estancia en Roma, el embajador imperial había demostrado su incapacidad para tal cargo. Absorto en el complicado formalismo de la Curia romana, centrado en cuestiones meramente accesorias, «umbroso e scontroso, [...] non sospettava nemmeno lontanamente di lavorare in tal modo, non pour le Roi de Prusse, ma pour le Roi de France» ${ }^{8}$, en un momento en el que las influencias eclesiásticas sobre Carlos II se controlaban, como es lógico, desde Roma. El cardenal de Bouillon, chargé d'affaires ante la Santa Sede (16971699), que había encontrado en su rival Martinitz un inesperado aliado, pudo así sacar ventaja de las tensiones entre Viena y Roma. Y no le resultó difícil elaborar un discurso político que acusaba al emperador Leopoldo de pretender declararse heredero de los antiguos romanos. Los franceses, y entre ellos el Cardenal, pudieron representar

«al pontefice Innocenzo XII, in maniere patetiche, cosa si potesse aspettare dalla casa di Austria germanica se questa entrava in possesso di Napoli e Sicilia, e dello stato di Milano con ricordare le avarie praticate nell'ultima guerra dagli imperiali coi popoli d'Italia, e le violenze usate in Roma dal conte di Martinitz»;

en cambio, nada habría que temer si la Monarquía pasaba a uno de los hijos del Delfín ${ }^{9}$ y los príncipes italianos formaban una liga para defenderse del austracismo que inquietaba las posesiones españolas de la Península, como quería Luis XIV ${ }^{10}$.

Pero hubo además otra circunstancia que acercó aún más al cardenal de Bouillon a la Curia romana: el apoyo que hizo público en Roma a Fénelon (finalmente condenado por Inocencio XII por presiones francesas) frente a Bossuet con su célebre defensa de la Explication des Maximes des Saints, dejando a un lado su labor diplomática y desentendiéndose de las indicaciones de París, le valió la condena de Luis XIV y su cese en el cargo ${ }^{11}$. Su negativa a regresar a Francia, como le exigía el rey, aunque relacionada con la posibilidad de ocupar el cargo de cardinal decano ante la probable muerte de su titular, Alderano Cybo-Malaspina, hizo que fuese muy bien considerado por los cardenales del grupo zelante, que quisieron ver en él una especie de antiguo mártir cristiano $^{12}$.

8 BRUNETTI, M.: op. cit. p. 205.

9 Muratori, L. A.: op. cit. pp 209-210. Este particular también lo recoge L. PASTOR, op. cit. p. 501.

10 Cfr. Hanotaux, G.: Recueil des instructions données aux ambassadeurs et ministres de France depuis les traitésde Westphalie jusqu'a la Revolution française, vol. XVII, París, 1911, p. 134.

11 Sobre de Bouillon y su caída en desgracia véase la biografía de REYSSIÉ, F.: Le cardinal de Bouillon (1643-1715), París, 1899.

12 El embajador veneciano Erizzo narra como Bouillon, que había emprendido el viaje de regreso a Francia pero que se había detenido en Caprarola, tras conocer la noticia del fallecimiento del cardenal Cybo-Malatesta (22 de julio de 1700), optó por regresar a Roma a tomar posesión del 
Pese a la simpatía que había producido este incidente en Roma, la desobediencia del cardenal hizo patente la necesidad de una representación francesa ante la Santa Sede de mayor rango, sobre todo, dada la importancia del momento y la influencia que el papa podía tener entre las potencias católicas. El elegido para esta delegación fue Luigi Grimaldi, príncipe de Monaco, que fue recibido por Inocencio XII en calidad de embajador el 27 de junio de $1699^{13}$, ocho años después de que el antiguo titular de este cargo, el duque de Chaulnes, hubiese abandonado Roma a petición del Rey. Aunque Grimaldi, como su homólogo imperial, dio mucha importancia a las cuestiones protocolarias, las instrucciones que recibió de Luis XIV, junto con un breve resumen de la política internacional del momento, no dejaban lugar a dudas sobre los objetivos de su misión ni permitían frivolidades: Francia debía mostrarse en Roma como una gran potencia militar, amante de la paz en Europa; había sido capaz de sacrificar en Ryswick las ventajas que le había procurado la Guerra de los Nueve Años por la tranquilidad general. Ahora estaba dispuesta a «maintenir la justice en faveur du légitime héritier» a la Corona de España ${ }^{14}$.

Cuando por fin Viena, tras percatarse de que «las cuestiones que el embajador Martinitz había movido en Roma le ocasionaban perjuicios» ${ }^{15}$, optó por relevar en el cargo a su representante, era ya demasiado tarde. El panorama que se encontró su sucesor, el conde de Lamberg, tras su llegada a Roma en enero de 1700 no podía ser más desolador para los intereses de la causa austriaca: Martinitz se había convertido en una figura aislada en la corte romana, había protagonizado un incidente con el embajador de España e incluso era reacio a colaborar con él. En definitiva, se había dejado llevar por simples cuestiones protocolarias y había descuidado el problema de la sucesión española (que tenía que haber sido su verdadera preocupación) y propiciado un conflicto diplomático entre el emperador y el pontífice justo a la vigilia de la esperada muerte de Carlos II. Sólo cuando el conde Martinitz abandonó Roma en el mes de marzo, sin audiencia de despedida, sin séquito y sin los honores propios de su condición, se pudo restablecer una cierta normalidad diplomática entre el Imperio y la Santa Sede ${ }^{16}$.

Los frutos de esa mejora de las relaciones entre Viena y Roma se tradujeron en la nómina a cardenal de Johannes Philipp von Lamberg, titular del obispado

\footnotetext{
decanato, pese a perder más de 80000 escudos en rentas que poseía en Francia y como la acción le valió el respeto de la mayoría de los cardenales. cfr. F. NiCOLINI, L'Europa durante la guerra di successione di Spagna, vol I, Nápoles, 1937, pp. 58-59.

13 Cfr. Hanotaux, G.: op. cit. p. 148.

14 Cfr. Instuction donnée par le roi a M. le prince de Monaco, duc de Valentinois, pair de France, chevalier des ordres de Sa Majesté, allant a Rome en qualité de son ambassadeur extraordinaire, Versalles, 28 de enero de 1699, ivi, pp. 158-159.

15 Castellví, F.: Narraciones históricas, vol. I, Madrid, 1998, p. 128.

16 Cfr. BRunetTi, M.: op. cit. pp. 220-222
} 
de Passau, el 21 de junio de $1700^{17}$. Aunque el nuevo embajador reverdecía los tradicionales lazos de amistad del emperador Leopoldo I con el papa Pignatelli, cultivados desde que éste ocupase la nunciatura de Viena, este éxito no era suficiente para sobreponerse a los fracasos cosechados por Martinitz. La perspectiva de un Reino de Nápoles amenazado por el galicanismo en el caso de que cayese en poder de los franceses, esbozada por Lamberg al pontífice, llegaba demasiado tarde ${ }^{18}$. Inocencio XII, casi sin el esfuerzo de la diplomacia francesa, estaba ya más próximo a la Casa de Borbón, justo cuando desde España, valorando las candidaturas imperial y francesa, se le pedía consejo sobre la designación del futuro heredero de la Monarquía.

\section{LAS PRETENSIONES DE ROMA EN EL REINO DE NÁPOLES.}

Durante la segunda mitad del siglo XVII — con el antecedente del Squadrone Volante ${ }^{19}$ en los años cincuenta- la Curia romana se empeñó en un proceso destinado a la desarticulación de las tradicionales facciones cardenalicias controladas por las grandes potencias europeas. La esperanza del Papado era reconstruir su autonomía en Roma y avanzar hacia una mayor influencia en la Península Itálica; muestra de ello fueron el dinamismo del grupo zelante y la abolición del cardinal-nipote durante el pontificado de Inocencio XII, quien no por ello, dejó de ser acusado de filofrancesismo. Esa aspiración de independencia se hizo aún más plausible en los años Noventa, ante las noticias de la probable extinción de la rama hispana de la Casa de Austria. La Curia pretendió aprovechar la coyuntura para luchar por la reconquista del liderazgo en Italia y poder, consecuentemente, condicionar, en la medida de lo posible, la política europea; dos objetivos que tenían como finalidad la vuelta al statu quo anterior a la paz de Westfalia ${ }^{20}$, que marcarían el futuro pontificado de Clemente XI (1700-1721) y su posicionamiento en la cercana Guerra de Sucesión española.

La estrategia para hacerse con la primacía de la península Itálica, si Carlos II moría sin descendencia, se centraba en Nápoles, lugar de procedencia de muchas de las familias de los cardenales en Roma. Este Reino era jurídicamente

17 Cfr. Ritzler, R. y Sefrin, P.: Hierarchia Catholica medii et recentioris aevi, V (1667-1730), Patavii, 1952, p. 22.

18 Cfr. BRunetTi, M.: op. cit. p. 223

19 Grupo de once cardenales que en el cónclave a la muerte de Inocencio X mostró su propósito de negarse a aceptar vetos por oposición de soberanos europeos para excluir del pontificado a candidatos que ellos consideraban dignos por prudencia, doctrina y piedad. Cfr. G. SigNOROTTO, "Lo Squadrone Volante. «I cardinali 'liberi' e la politica europea nella seconda metà del XVII secolo»", en SignOROTTO, G. y Visceglia, M. A.: op. cit. pp. 93-137

20 Cfr. TABACCHI, S.: L'Impossibile neutralità. Il Papato, Roma e lo Stato della Chiesa durante la Guerra di Successione spagnola, en ÁlvareZ-OSsorio AlvariÑo, A.: Famiglie, nazioni e Monarchia durante la Guerra di Successione spagnola. "Cheiron». 39-40, 2003, p. 224 
un feudo de la Iglesia, que se otorgaba, mediante juramento de vasallaje, a los monarcas españoles titulares de la Corona de Aragón, que desde época medieval dominaba este territorio. La concesión de la investidura, aunque era en realidad un hecho puramente protocolario, en el que el vasallo recibía el feudo a cambio de una hacanea blanca y el pago de 12.000 escudos de oro en la víspera de la fiesta de San Pedro y Pablo, podía ser utilizada en un futuro no muy lejano, como así hubiera de ocurrir ${ }^{21}$, para presionar a España y a su nuevo rey y exigir, a cambio, algunas contrapartidas que subsanasen ciertos atropellos a la jurisdicción eclesiástica en el sur de Italia. Sin embargo, en la década de los Noventa del siglo XVII, lo que preocupaba a la Iglesia no era tanto la falta de respeto a sus privilegios como el incipiente desarrollo del jurisdiccionalismo napolitano, que ponía de nuevo al descubierto la tradicional polémica sobre las discutidas inmunidades que la Santa Sede gozaba en el Reino. El jurisdiccionalismo maduró como base teórica a una reacción a la causa abierta contra Basilio Giannelli y Giacindo De Cristofaro por el Santo Oficio en 1693 (processo agli ateisti) ${ }^{22}$, si bien pronto sirvió para aglutinar ideas inspiradas en el iusnaturalismo presentes en la literatura filosófica partenopea de la segunda mitad del XVII que apostaban, sin caer en visiones arcádicas, por el mantenimiento de las libertades civiles y por una clara toma de consciencia política del ceto civile ${ }^{23}$. Ya fuera por la oposición a cualquier novedad en la praxis de la Inquisición, por las controversias que estudiaba la Delegación de la Real Jurisdicción desde el punto de vista laico, por la creciente intolerancia a los inconvenientes derivados del derecho de asilo y de los privilegios del foro eclesiástico o por la defensa de cualquier intento de ir más allá de lo nominal en el vínculo feudal del Reino con Roma, el anticurialismo había estado presente en Nápoles durante todo el siglo XVII ${ }^{24}$.

Partiendo de estas bases, el jurisdiccionalismo propugnaba la defensa del Estado y de su autonomía jurídica (jurisdicción real) frente a los privilegios del estamento eclesiástico, sobre todo en lo referente a las inmunidades; y la necesidad de apoyar a las nuevas corrientes filosóficas y científicas, como una demostración de libertad frente al continuismo; protestaba, sobre todo, contra el debilitamiento del poder judicial civil; y se mostraba como un punto de reunión de los grupos cultos napolitanos (con Nicola Caravita y Giuseppe Vallet-

21 El 8 de noviembre de 1700, una semana después de la muerte de Carlos II, monseñor Acquaviva, nuncio en España, presentaba una nota pública en Madrid en la que se referían los derechos de la Santa Sede sobre los reinos de Nápoles y Sicilia y su potestad para concederlos «mediante la legitima Investitura». Cfr. ASV, Segr. Stato, Spagna, 182, ff. 453-454.

22 Sobre este proceso véase el capítulo que le dedica GALASSO, G.: en «Napoli nel viceregno spagnolo dal 1697 al 1707», en VVAA, Storia di Napoli, vol VII, Nápoles, 1972, pp. 55-85; y OSBAT, L.: L'Inquisizione a Napoli. Il processo agli ateisti 1688-1697, Roma, 1974.

23 Cfr. De Giovanni, G.: La vita intellettuale a Napoli fra la metà del '600 e la restaurazione del regno, en VVAA, Storia del Regno di Napoli, vol. VI*, Nápoles, 1971-72, pp. 424-428.

24 Cfr. Galasso, G.: op. cit. pp. 31-32. 
ta, entre otros) y las autoridades de la Monarquía española en la ciudad ${ }^{25}$. La frágil «alianza» - pero «alianza», al fin y al cabo- fue especialmente mimada por Luis Francisco de la Cerda, duque de Medinaceli, quien, durante su virreinato (1696-1702), mediante el mecenazgo de su Accademia, trató de ganarse a los intelectuales napolitanos ${ }^{26}-\mathrm{y}$ con ellos su influencia en los estamentos privilegiados - para conservar la lealtad del Reino y acallar las voces que comenzaban a pedir mayor libertad en el caso de que Carlos II muriese sin descendencia, independientemente de la procedencia del nuevo heredero.

La complicidad de las autoridades españolas en las teorías sobre la desvinculación de la tradicional influencia de la Iglesia en Nápoles era vista con malos ojos desde Roma. De hecho, aunque ya después de la subida del duque de Anjou al trono de España (pero sin haberse concedido aún la investidura de Nápoles) Clemente XI (1700-1721), en una audiencia concedida el 6 de mayo de 1701 al embajador veneciano en Roma Niccolò Erizzo, reflexionando sobre esta situación en el último siglo y medio, denunciaba como, mediante los continuos agravios de los españoles,

«Nel Regno la giurisdizione eclesiástica è ridotta quasi a nulla. I vescovi sono chiamati ogni momento dai viceré ad audiendum verbum regium; parecchi vengono sfrattati; e nell'esercitare il foro eclesiastico trovano, in tutte le diocesi, ostacoli d'ogni sorta» 27 .

En Roma se temía, sobre todo, que esas supuestas violaciones de la inmunidad eclesiástica, castigadas por el Derecho canónico, encontrasen refugio en el jurisdiccionalismo; de ahí que la Curia romana considerase la restauración de los conculcados derechos de la Iglesia una premisa básica para poder, como era norma, conceder la investidura, fuese quien fuese su teórico titular ${ }^{28}$. Antes de entrar a valorar las posibilidades de franceses e imperiales y sus posibles derechos, se exigía el reconocimiento total y absoluto del poder de Roma sobre el reino de Nápoles por ser feudo de la Iglesia.

\section{LA CONSUlTA DE CARLOS II.}

Tras la muerte del príncipe elector José Fernando de Baviera el 6 de febrero de 1699, designado heredero por Carlos II en dos ocasiones, las opciones reales de sucesión al trono de España quedaron reducidas a dos candidatos: el duque

25 Cfr. De Giovanni, B.: op. cit. , pp. 432-438.

26 Cfr. Ricuperati, G.: «L'immagine della Spagna a Napoli nel primo Settecento: Vico, Carafa, Doria e Giannone», en MusI, A. (ed.), Alle origini di una nazione. Antispagnolismo e identità italiana, Milán, 2003, p. 84.

27 Nicolini, F.: op. cit., vol. II, Nápoles, 1938, p. 185.

28 Cfr. Galasso, G.: op. cit., p. 183. 
de Anjou y el archiduque Carlos. El fallecimiento del príncipe dejaba a Madrid sumida en la confusión y el 28 de abril un típico motín de subsistencia, aprovechado por la oposición política, provocaba el fin del gobierno presidido por Joaquín Álvarez de Toledo, conde de Oropesa, que fue desterrado ${ }^{29}$. Con la caída del conde los austracistas perdían a un estandarte de sus aspiraciones y los francófilos, en cambio, dirigidos por el cardenal Portocarrero, ganaban posiciones en la carrera por la sucesión ${ }^{30}$.

En 1700 el hipotético reparto de las posesiones de Carlos II entre las potencias europeas, como se había intentado en La Haya ya el 11 de junio de 1699 sin el apoyo del emperador Leopoldo, se mostraba aún más evidente con la firma definitiva de este Segundo Tratado de Partición el 25 de marzo en esa misma ciudad. Una seria amenaza a la integridad territorial se cernía sobre la Monarquía. El 20 de mayo uno de los muchos ejemplares ${ }^{31}$ del acuerdo firmado por Francia, Inglaterra y Holanda fue enviado a Madrid por Castelldosríus. Al embajador le había proporcionado la copia de los acuerdos Jean-Baptiste Colbert, marqués de Torcy,

«a fin de saber su Amo sí Vuestra Magestad [Carlos II] querrìa consentir en ellos aprovandolos, o no, porque en caso de aprovarlos, quedarían todos gustosos, y en el de no, se tomarían las medidas que les pareciessen mas importantes a fin de la quietud publica, con cuyo motivo se havrían ajustado, para el contingente de no tener hijos Vuestra Magestad, por que teniendolos (como se los desseaba con todo su corazon) zerraba todo el motivo que les habría obligado a esta precauzión y providencia[...]» 32

El tono amenazador del ministro francés que se recogía en la carta debió causar un gran impacto tanto en la corte española como en la persona de Carlos II. La noticia —decía el nuncio Archinto- «ha sorpresso questa Maestà» ${ }^{33}$.

29 Sobre el episodio véanse las interpretaciones de EGIDO, T.: El motín madrileño de 1699, en «Investigaciones Históricas», 2, 1999 y RiBOT, L. A.: «La España de Carlos II», en VVAA., Historia de España fundada por Ramón Menéndez Pidal. La Transición del siglo XVII al XVIII, tomo XXVIII, Madrid, 1997, pp. 132-134.

30 Cfr. Domínguez Ortiz, A.: Testamento de Carlos II (Introducción), Madrid, 1982, p. XLV y Kamen, H.: La España de Carlos II, Barcelona, 1981, p. 609.

31 Aunque es evidente que hubo de haber un gran número de ejemplares en circulación no creo que fuese el nuncio monseñor Archinto quien entregase al gobierno de Carlos II una copia del tratado (Cf. KAMEN, H.: op. cit. pp. 610-611; o MAURA, D.: Vida y Reinado de Carlos II, vol. III, Madrid, 1942, p. 348), ya que no da cuenta de tener en su poder una copia del acuerdo a la Secretaría de Estado hasta el 24 de junio de 1700, diez días después de que Carlos II enviase la consulta sobre la sucesión a Inocencio XII, cfr. ASV, Segr. Stato, Spagna, 182, f. 192.

32 Carta de Castelldosríus a Carlos II anexa a una copia del Segundo Tratado de Partición de La Haya, ASV, Instr. Misc. 5933, ff. 19-22.

33 Correo del nuncio Archinto al secretario de Estado cardenal Espada. ASV, Segr. Stato, Spagna, 182, ff.178-179. 
Tanto era así que el Rey, al poco de regresar de su estancia en Aranjuez a principios de junio, convocó a los consejeros de Estado para que diesen su parecer sobre estos nuevos acontecimientos. La opinión que prevaleció, defendida por Portocarrero, Mancera, Villafranca, Santiesteban y el marqués del Fresno, era favorable a un testamento que designase como heredero a uno de los nietos de Luis XIV, preferentemente el hijo segundo o tercero del Delfín, con pocas posibilidades, por tanto, de subir al trono francés. Se acordó también escribir una carta a Inocencio XII para conocer su opinión y obtener una sanción de la decisión tomada en España. El parecer del Papa contaba mucho en Madrid. Sobre todo gracias a Portocarrero, quien, según Muratori, empleó «i suoi migliori ufizzi in favore della real corte di Francia», por consejo de Roma, y persuadió al monarca para escuchar a la Sede Apostólica ${ }^{34}$. La extrema incertidumbre que padeció Carlos II durante sus últimos días y los remordimientos que le causaba optar por una decisión que podía poner en peligro el Imperio que había heredado le hacían mirar, por sugerencia del cardenal, a la Religión. La necesidad de contar con el sólido respaldo de un árbitro aparente justificaba, en mayor medida, la consulta a Roma desde un punto de vista moral. Por más que el Papa tuviese los intereses propios de un príncipe temporal en la política italia$n a$, era el jefe de la Iglesia católica y estaba destinado a dar un juicio neutral sobre el posible heredero.

El 14 de junio escribía, pués, el Rey al Pontífice pidiéndole consejo sobre la sucesión ${ }^{35}$. Pese a que se daba ya por informado a Inocencio XII de las intenciones de varias potencias europeas de dividirse la Monarquía, se incluyó también en el correo una copia del Segundo Tratado de Partición de La Haya ${ }^{36}$ que certificaba la gravedad del proyecto. El peligro que el acuerdo suponía para España — se decía en la carta - era también una amenaza para parte de la Cristiandad, que caería en manos de ingleses y holandeses (herejes, según la Europa católica). Y aunque Carlos II no perdía la esperanza de evitar una situación tan comprometida ya que su «confianza y fee viva en la Divina providencia» le aseguraban la vida y la sucesión, comprendía que era necesario, si él muriese sin descendencia, elegir un heredero para evitar que se extendiese la incertidumbre entre sus vasallos. Sus ministros, decía el Rey, le habían aconsejado que optase por un candidato de la Casa de Borbón. Era entonces el momento de conocer el dictámen de Inocencio XII para que así «tome yo [Carlos II] el mas firme, a la seguridad, de mantener inseparables los Reynos de mi Corona, la Sagrada Religión, y sus cultos» ${ }^{37}$.

\footnotetext{
34 MUratori, L. A.: op. cit., p. 210

35 Consulta de Carlos II a Inocencio XII. ASV, Instr. Misc. 5933, ff. 5-6.

36 Londres, 3 de marzo de 1700. ASV, Instr. Misc. 5933, ff. 9-18.

37 Consulta de Carlos II a Inocencio XII. ASV, Instr. Misc. 5933, ff. 5-6.
} 


\section{LA RESPUESTA DEL PAPADO}

El 3 de julio de 1700 el duque de Uceda entregó al pontífice el correo urgente con la consulta de Madrid que apenas había recibido ${ }^{38}$; toda la documentación reservada estaba avalada por una carta en la que se recomendaba al embajador en Roma ${ }^{39}$. La Santa Sede debía pronunciarse sobre la cuestión sucesoria.

El relato ${ }^{40}$ que el cronista Francesco Maria Ottieri hizo en su Libro Terzo de la Istoria de la Guerra de Sucesión española sobre los días transcurridos desde ese momento hasta que la respuesta del Papa fue entregada al embajador español es particularmente ilustrativo. Según él, tras recibir el correo de la corte española, Inocencio XII convocó en una reunión a los cardenales ${ }^{41}$ Fabrizio Spada, Giambattista Spinola y Giovanni Francesco Albani para que estudiasen la documentación remitida y se pronunciasen al respecto. Fabrizio Spada, nacido en Roma en 1643 en el seno de la familia de los marqueses de Castelvicardo, había sido nuncio en Saboya y Francia en los años 70 del siglo XVII y desempeñaba en ese momento el cargo de secretario de Estado; Giambattista Spinola, que ostentaba el cargo de cardenal camarlengo, era natural de Génova (1646) y no contaba, en cambio, con experiencia en política internacional. Por último, Giovanni Francesco Albani, proveniente de una rica familia patricia de Urbino, donde nació en 1649, había participado activamente, junto con el cardenal Janson, en la reactivación de las buenas relaciones entre Francia y Roma promovidas en el pasado por Urbano VIII; se ocupaba de la Secretaría de los Breves Apostólicos desde hacía trece años; famoso por su participación en la bula contra el nepotismo de 1696 y por su prometedora carrera, habría de ser elegido pontífice con el nombre de Clemente XI en el futuro cónclave. Hay quien también incluye al cardenal Panciatici en la congregación ${ }^{42}$.

Dada la gravedad del asunto, las instancias del duque de Uceda para conocer el parecer de Roma y poder enviar una respuesta precisa a Madrid eran constantes. Finalmente, tres días después de que la carta de Carlos II llegase a

38 Cfr. PASTOR, L.: op. cit. p. 505.

39 Carta autógrafa de Carlos II a Inocencio XII, ASV, Instr. Misc. 5933, ff 2-3

40 OTTIERI, F. M $\mathbf{M}^{\mathrm{a}}$ : Istoria delle guerre avvenute in Europa e particularmente in Italia per la successione alla monarchia delle Spagne dall'anno 1696 all'anno 1725, tomo I, Roma, 1728, pp 388-391

41 Para Fabrizio Spada véase AgO, R.: Carriere e clientele nella Roma barocca, Bari, 1990; y Ritzler, R.-SEFrin, P.: Hierarchia Catbolica medii et recentioris aevi, V (1667-1730), Patavii, 1952, pp 9 y 309. Para Giambattista Spinola CARdella, L.: Memorie storiche de' cardinali della Sacra Romana Chiesa, vol. 8., Roma, 1794, pp. 49-50; y RITZLER, R.-SEFrin, P.: op. cit. pp. 11 y 226. Con respecto a Giovanni Francesco Albani, consúltese ANDRETTA, S.: Clemente XI en VVAA, Enciclopedia dei Papi, ***, Roma, 2000, pp. 405-420; CARdella, L.: op. cit. pp. 19-24; PometTi, F.: Studi sul pontificato di Clemente XI (1700-1721), "Archivio della Regia Società Romana di Storia Patria», XXI, 1898, pp. 304-306; y RITZLER, R.-SEFRIN, P.: op. cit, p. 17.

42 Polidori, P.: De Vita et rebus gestis Clementes Undecimi, Libro I, Urbino, 1727, p. 40; y F. PometTi, op. cit, p. 303; citan a este cardenal. OTTIERI, F. M a : op. cit., p. 389 y PASTOR, L.: op. cit., p. 505, en cambio, no hacen ninguna referencia. 
manos de Inocencio XII se tomaba una decisión. El 6 de julio, después de que el secretario de Estado cardenal Spada se trasladase hasta en dos ocasiones del Quirinal al Palacio de la Embajada de España, «con grandissima ammirazione di Roma» por ser algo poco habitual, se entregó un correo urgente al duque de Uceda $^{43}$. Aunque se desconoce exactamente la opinión y votos de cada uno de los cardenales, sí se tiene constancia del contenido de la respuesta. El pontífice, hablando de su parecer, «stimava non doverci discostare da quello del suo real Consiglio fondato sul necesario principio di assicurare nel più riuscibil modo che si può l'unione, e conservatione intiera della Monarchia» ${ }^{44}$. Roma daba el beneplácito a las tesis de la mayoría de los Grandes que habían aconsejado al monarca.

La opinión de la Santa Sede fue, por lo tanto, clave para que, meses después, Carlos II, al redactar el testamento, nombrase al duque de Anjou su heredero. Se esperaba que la integridad territorial de la Monarquía española, tras el miedo provocado en el país por los tratados de partición, estuviese a salvo gracias al poderío militar de los franceses. La decisión de aceptar o no el testamento quedaba en manos de Luis XIV, quien se debatía entre permitir a su nieto proclamarse rey de España o acatar lo acordado en el Segundo Tratado de Partición y no provocar a las otras potencias firmantes. Cuando por fin se conoció que Francia aceptaba que un Borbón, como había dictado Carlos II, reinase en España, a algunos no les sorprendió la noticia. El duque de Moles, embajador español en Viena, por ejemplo, manifestó que

«a questo risultato appunto volesse giungere sin dal primo momento il Cristianissimo, e che la stipulazione e sopra tutto la pubblicazione del trattato di partizione non fossero state, da parte sua, se non un abile mezzo per esasperare l'opinione pubblica spagnola, avversa a qualunque smembramento della monarchia, e forzare, per tal modo, la mano del defunto re cattolico» ${ }^{45}$.

Fuese cierta o no esta hipótesis, a la muerte de Carlos II la Monarquía española pasaba íntegramente a un hijo del Delfín y la opinión del Papa, como habría de reconocer el propio Portocarrero en una carta al cardenal Spada, según recoge Janson, había sido determinante ${ }^{46}$. Felipe $\mathrm{V}$ era el nuevo rey de España.

43 OTTIERI, F. M M $^{\mathrm{a}}$ : op. cit. pp. 390-391

44 Copia de la respuesta de Inocencio XII a Carlos II. ASV, Instr. Misc. 5933, ff. 23-25.

45 Así lo refería Loredan, embajador veneciano en Viena en una carta al senado de la República el 27 de noviembre de 1700. Cfr. NiCOLINI, F.: L'Europa durante la guerra di successione di Spagna, vol. I, Nápoles, 1937, p. 206

46 BLET, P.: Le Clergé de France. Louis XIV et le Saint Siège de 1695 a 1715, Ciudad del Vaticano, 1989, p. 152. 


\section{LA DOCUMENTACIÓN}

La consulta de Carlos II a Inocencio XII sobre la sucesión, junto con la carta autógrafa que la avala, y la respuesta manuscrita del pontífice (copia con la que obviamente se quedó la Santa Sede) forman parte del legajo 5933 del fondo Instrumenta Miscellanea ${ }^{47}$ del Archivio Segreto Vaticano. Esta unidad está compuesta además por una copia del Segundo Tratado de Partición de La Haya y una carta del embajador español en París (vid. supr).

La consulta al poder espiritual sobre la sucesión ha sido un tema muy debatido por la historiografía no tanto por el tenor de la respuesta del pontífice —en la que todos los estudiosos coinciden- como por la documentación en sí, ya que los supuestos originales que se dieron a conocer en el siglo XIX son del todo falsos ${ }^{48}$. Los documentos que aquí se presentan escapan, sin embargo, de toda polémica, y sobre todo, de la posibilidad de que la respuesta del pontífice al monarca español hubiese sido falsificada. Es ésta una hipótesis que en este caso carece de fundamento ya que resulta incoherente e ilógico que la Santa Sede «falsificase» a si misma un documento en el que se mostraba favorable a la opción borbónica — por otra parte, manuscrito del papa Pignatelli-, copia del que hubo de enviarse al último Austria. El verdadero parecer de Inocencio XII sobre el heredero a la Monarquía española coincide con el que tradicionalmente se le había atribuido.

\section{Carta de Carlos II a Inocencio XII}

ASV, Instr. Misc. 5933, ff. 5-6 (ff. 7r-8v en blanco).

Madrid, 14 de junio de 1700

[f. $5 r$ \}Muy Santo Padre. Bien informado se hallara Vuestra Santidad de la capitulación stipulada, entre el Rey Christianísimo, el de Ynglaterra, y Estados Generales de Holanda, con el motivo, de considerarme en la menos salud que la que nuestro Señor por su infinita misericordia, ha vuelto a prestarme, y de haver hecho concepto, de que me faltara la sucesión, y la Vida, para cuyos cassos, y pretextando la conserbacion de la Paz, y reposo de la Europa, y evitar las encendidas Guerras, que ocassionarían, las pretensiones, de los que intentasen tener mejor derecho a mis Reynos, los separan y distribuyen, como Vuestra Beatitud havra entendido, y reconocera de las copias inclusas de el Proyecto, y carta de mi Embaxador en París; de que tambien se infiere, sin la menor duda, la gran parte de Christiandad, que en las Yndias, y algunas Yslas se repartiran Juntamente a Ingleses $[f .5 v]$ y Holandeses, como partícipes en estos tratados, y Garantes de su cumplimiento, y observancia, para lo qual havra otro reservado pacto, y convenio; $\mathrm{Y}$ aunque mi confianza, y fee

47 Sobre este fondo véase el inventario de Milian Boix, M.: El Fondo «Instrumenta Miscellanea» del Archivo Vaticano, Roma, 1969.

48 Cfr. PAstor, L.: op. cit., pp. 505-506. Se hace eco de esta teoría Domínguez OrTiz, A.: Regalismo y relaciones Iglesia-Estado en el siglo XVII, en GARCía VILlOSLADA, R.: Historia de la Iglesia en España, Madrid, 1979, pp. 88-89. 
viva en la Divina providencia, me assegura la Vida, y la successión, correspondientes a mì edad y Estado; todavìa, siendo tan catholico, como amante de la universal tranquilidad de el Mundo, y tan atento, como obligado, a mirar la conserbacion de la Sagrada Yglessia Chatolica Romana, y que sus Hijos y Fieles no padezcan los peligros, tribulaciones, y angustias, en que pudieran hallarse con tan ciertos, y horrorosos riesgos, como se experimentarían con dolor grande, de la Santa Sede, si llegase el casso, de que por mis graves, y muchos pecados, viesen mis Reynos, la fatal desgracia de mi ultima hora, sin dejarles succession mia, o providencia tal, que la supla, sin embarazo, y oposicion; y conssiderando mis primeros Ministros, que esta felicidad, puede facilmente conseguirse $[f$. 6r]constituyendo en el llamamiento, de mi successor, y para el entero dominio de mis Reynos a uno de los Hijos Segundos de el Serenissimo Delphin de Francia, me lo aconsejan y proponen; Y desseando yo, que, como devo, permanezca en todos mis Reynos la pureza y Religion, que tan radicada, mantubieron mis passados, y a tantas expensas, y cuydado mì, he procurado subsista, y se augmente, he querido para este fin, offrecer a Dios en su Yglessia, el sacrificio de la propia voluntad poniendo (como lo hago) mis resoluciones, y mis Reynos, en las Santas manos de Vuestra Beatitud, para que como Padre universal, Regimen, y auxilio de todos los Monarchas, sea Vuestra Santidad quien dirija mis operaciones, y yo assegure, las que tanto desseo, con el acertado Consejo de Vuestra Beatitud, con sus officios Paternales, con su mediación suprema, y con la infalible verdad de su determinación, para que entendido el rectissimo dictamen de Vuestra Santidad, que hallando los effectos de su Santo acuerdo, tome yo el mas $[f .6 v]$ firme, a la seguridad, de mantener inseparables los Reynos de mi Corona, la Sagrada Religion, y sus cultos y cumpla cavalmente, todas las obligaciones de mi cargo y todos los fueros de mi conciencia. Nuestro Señor guarde a Vuestra Beatitud como desseo. De Madrid a 14 de junio de 1700.

Muy Humilde hijo de Vuestra Santidad. el Rey

Risposta data di S. Sa scritta di proprio pugno alla lettera di S. $M^{a}$ scritta parimente di pugno suo in data 14 giugno 1700 che ne fù portata e lasciata in mani del S. Ambe. Duca d'Uceda, asviene cosi la copia di detta resposta.

ASV, Instr. Misc., 5933, ff. 23-25.

Roma, 6 de julio 1700.

[f. 23r]Innocentius Papa 12.

Charissime in Christo filiem nostrem salutem, et Apostolicam benedizionem.

Dall'Ambasciadore di Vostra Maestà ci è data nella sua real carta in data de' 14 del passato mese di Giugno, con la quale inviandoci copia del trattato, che sopra la divisione de' suoi regni, e dominii in caso della mancanza, che Iddio non permetta di Vostra Maestà senza successione, è stato concluso tra li plenipotentiarii di Francia, Inghilterra, e d'Olanda, ella ci complace di parteciparci, come il suo real Consiglio per il bene de suoi sudditi, per la sicurezza Maggiore della publica tranquilità, e per l'interesse principalmente della Religione Cattolica, giudicando, che la Maestà Vostra sia in precisa obligatione di cenare ogni possibile maniera di conservare intiera la Monarchia che Iddio gli hà data, e per evitare qualunque divisione della medesima propone, e consiglia alla Maestà Vostra per il più sicuro modo da conseguir $\{f .23 v]$ l'intento il chiamar succesore alla sua Corona 
in mancanza di prole uno de' secondi figli del Delfino di Francia; sopra la qual propositione e consiglio, che ogn'un ben vede di quanta grave importancia pasa là Maestà Vostra a chiederci con premurosa instanza il nostro parere presso i nostri ufficii per quello che susseguentemente puoli occorrere. Ben conosciamo quanto plenamente ci unisca all'insigne pietà della Maestà Vostra e a quel figliale rispetto che ereditato dai suoi gloriosi antenati ella hà sempre professato verso di questa Santa Sede la confidenza, che ci fa in affare sí grande, corrispondala perciò noi alla medessima dal canto nostro con la dovuta sincerità siamo in obligo di dirle, che se bene speriamo che il Signor Iddio sia per conservare lunga serie d'anni, e con perfecta salute la tanto necesaria e pretiosa vita di Vostra Magestà, anzi sia anco per degnarsi di consolare un giorno le universali brame Della Cristianità concedendole la aspirata prole, come $[f$. 24r] del continuo ne porgiamo ferventi, e incessanti voti alla infinità misericordia, non dimeno non alo animamente lodiamo, mà necesaria, $\mathrm{e}$ digna per ogni atto della incomparabile premura, ch'ella tiene di oportunamente provedere anco à quei casi, che per desventura del mondo christiano potevano darsi in contrario. Quindi è, che benche molto ci habbia dato la sua lettera, in cui ben veggiamo, e di tutto cuore compartiamo la angustia, che prova l'animo suo reale in sí ardua deliberatione, netl tempo stesso però vedendo, come in sí grave emegenza la Maestà Vostra ci prefigge per primo sopra il maggior servitio d'Iddio, il ben della sua Chiesa, e la preservatione della Nostra Santa Religione da quei pericoli, che potrebbero temerse, volendo anteporre queste considerate ad ogn'altro motivo, che ci la presenta, ci humiamo anco di che infinitamente consolarci onde habbiamo grand'orazione di $[f .24 \mathrm{v}]$ di confidare, che la Divina Bontà sia per assistere, come con caldissime preghiere la supplichiamo alla rettissima intentione di Vostra Magestà dandole tutti quei lumi, che ano necessarii per accetare quella risolutione che puol'esser per più oportuna al conseguimento di un fine sí giusto. E poiche Vostra Magestà ci costringe a dirle sopra di ciò il nostro sentimento stimiamo di non doverci discostare da quello del suo real Consiglio fondato sul necesario principio di assicurare nel più riuscibil modo che si può l'unione, e conservatione intiera della Monarchia. Quanto poi agl'ufficij, che la Maestà Vostra ci si chiede, non lasciaremo di efficacemente interporli sempre che possano riputarsi opportuni e profittevoli per tutto ciò, che in sí importante contingenza però convenire alla nostra obligatione, e all'amore tenerissimo, con cui ..iamo la persona della Maestà Vostra $[f$. 25r]alla quale intanto co' più affetuosi e cordiali sentimenti dell'animo diamo la nostra Apostolica, e paterna bendedictione.

Datum Romae apud Santa Maria Maiore die 6 Julii 1700 Pontificatus nostrum anno 9.

\section{Abreviaturas:}

$$
\begin{aligned}
\text { ASV }= & \text { Archivio Segreto Vaticano. } \\
& - \text { Segr. Stato, Spagna, }=\text { Segreteria di Stato, Spagna. } \\
& - \text { Instr. Misc. = Fondo Instrumenta Miscellanea. }
\end{aligned}
$$

